\title{
Quorum sensing signal molecules (acylated homoserine lactones) in Gram-negative fish pathogenic bacteria*
}

\author{
Jesper B. Bruhn ${ }^{1, * *}$, Inger Dalsgaard ${ }^{2}$, Kristian F. Nielsen ${ }^{3}$, Christiane Buchholtz ${ }^{1}$, \\ Jens L. Larsen ${ }^{4}$, Lone Gram ${ }^{1}$ \\ ${ }^{1}$ Danish Institute for Fisheries Research, Department of Seafood Research, Søltoft Plads c/o Technical University of \\ Denmark bldg. 221, 2800 Kgs. Lyngby, Denmark \\ ${ }^{2}$ Danish Institute for Fisheries Research, Fish Disease Laboratory, Stigbøjlen 4, 1870 Frederiksberg, Denmark \\ ${ }^{3}$ Centre for Microbial Biotechnology, Technical University of Denmark bldg. 221, 2800 Kgs. Lyngby, Denmark \\ ${ }^{4}$ Department of Veterinary Pathobiology, Stigbøjlen 4, Royal Veterinary and Agricultural University, \\ 1870 Frederiksberg C, Denmark
}

\begin{abstract}
The aim of the present study was to investigate the production of quorum sensing signals (specifically acylated homoserine lactones, AHLs) among a selection of strains of Gram-negative fish bacterial pathogens. These signals are involved in the regulation of virulence factors in some human and plant-pathogenic bacteria. A total of 59 strains, representing 9 different fish pathogenic species, were tested against 2 AHL monitor bacteria (Agrobacterium tumefaciens NT1 [pZLR4] and Chromobacterium violaceum CV026) in a well diffusion assay and by thin-layer chromatography (TLC). Representative samples were further characterized by high performance liquid chromatography-high resolution mass spectrometry (HPLC-HR-MS). AHLs were produced by all strains of Aeromonas salmonicida, Aeromonas hydrophila, Yersinia ruckeri, Vibrio salmonicida, and Vibrio vulnificus. Some strains of atypical Aeromonas salmonicida and Vibrio splendidus were also positive. Aeromonas species produced $N$-butanoyl homoserine lactone (BHL) and $N$-hexanoyl homoserine lactone (HHL) and 1 additional product, whereas $\mathrm{N}$-3-oxo-hexanoyl homoserine lactone (OHHL) and HHL were detected in Vibrio salmonicida. $\mathrm{N}$-3-oxo-octanoyl homoserine lactone (OOHL) and $\mathrm{N}$-3-octanoyl homoserine lactone (OHL) were detected in Y. ruckeri. AHLs were not detected from strains of Photobacterium damselae, Flavobacterium psychrophilum or Moritella viscosa. AHLs were extracted from fish infected with Y. ruckeri but not from fish infected with $A$. salmonicida. In conclusion, the production of quorum sensing signals, AHLs, is common among the strains that we examined. If the AHL molecules regulate the expression of the virulence phenotype in these bacteria, as shown to occur in some bacterial pathogens, novel disease control measures may be developed by blocking AHL-mediated communication and suppressing virulence.
\end{abstract}

KEY WORDS: Quorum sensing · Signal molecules · Acylated homoserine lactones ·AHL · Fish pathogenic bacteria

Resale or republication not permitted without written consent of the publisher

\section{INTRODUCTION}

Bacterial disease is a constraint in modern fish farming and, therefore, successful fish farming requires control of infectious diseases, which may spread rapidly during intensive production. Bacterial diseases are traditionally treated with antibiotics; however, a major concern about this approach is the frequent

${ }^{*}$ Part of this paper was presented as a poster at the 2nd ASM Conference on Cell-Cell Communication in Bacteria, Banff, Alberta, Canada

**Email: jbb@dfu.min.dk development of resistance to antibiotics in fish pathogenic bacteria and the release of antibiotics to the environment (Tsoumas et al. 1989, DePaola et al. 1995, Schmidt et al. 2000). Alternatives to antibiotics, such as vaccines, have in some cases been very successful; however, new methods for controlling bacterial diseases are needed in situations where vaccines cannot be applied.

(C) Inter-Research $2005 \cdot$ www.int-res.com 
Regulation of virulence factors is important for the infection and transmission cycle of fish pathogenic bacteria and new non-antibiotic based treatments, which directly inhibit expression of virulence factors rather than the growth of the bacteria, could be envisaged. The advantage of such an approach would be that the bacteria do not develop resistance since they are neither killed nor is their growth inhibited. In this context, an understanding of the regulation of virulence factors is absolutely central. Virulence is under the control of a so-called quorum sensing (QS) system in a number of Gram-negative bacteria (Jones et al. 1993, Winans et al. 1999). The vast majority of studies on QS systems have been directed towards human or plant pathogenic bacteria where a detailed understanding of the virulence regulation has been developed (Whitehead et al. 2001). However, QS systems have also been detected in some fish pathogenic bacteria such as Aeromonas hydrophila (Swift et al. 1999), Vibrio vulnificus (Kim et al. 2003), Vibrio harveyi (Freeman \& Bassler 1999) and Vibrio anguillarum (Croxatto et al. 2002, Buch et al. 2003). QS systems rely on the ability of the bacteria to monitor their population cell density by releasing small molecular mass signal molecules (mainly acylated homoserine lactones [AHLs] for Gram-negative bacteria) into the environment. The bacteria can sense their cell density by monitoring the concentration of these signal molecules, and thereby trigger specific phenotypes (for example, virulence factors) at a particular cell density (Eberl 1999, de Kievit \& Iglewski 2000, Whitehead et al. 2001). From the bacterial point of view, the advantage of using a QS system during infection is to evade the host immune system. Hence, the 'aggressive' phenotypes which can be recognized by the immune system of the host are not produced until the cell density is sufficient to overcome the immune system.

Some molecules, so-called quorum sensing inhibitors (QSI), may specifically block the AHL-regulated systems, and thereby the expression of virulence factors, at concentrations where growth of the bacteria is not affected. An example of such compounds is the halogenated furanones from the red algae Delisea pulchra (Givskov et al. 1996) which specifically block expression of virulence factors in Pseudomonas aeruginosa (Hentzer et al. 2003), Vibrio harveyi (Manefield et al. 2000) and Erwinia carotovora (Manefield et al. 2001). These compounds have therefore been suggested as a new treatment for controlling bacterial disease. It has recently been demonstrated that the halogenated furanone C30, which was added to the water during a trout co-habitant challenge experiment with $V$, anguillarum, caused a significant reduction in accumulated mortality compared to the untreated control. The concentrations of furanone C30 used had no effect on the growth of $V$. anguillarum (Rasch et al. 2004).

We have previously shown that most strains of Vibrio anguillarum produce AHL molecules and that these compounds are present during infection of fish (Buch et al. 2003). Other studies have shown that AHLregulated phenotypes may influence virulence in $V$. anguillarum, but no direct link has been found between QS and virulence (Croxatto et al. 2002).

To maintain a QS system, the fish pathogens have to produce signal molecules (e.g. AHL molecules). AHL molecules have been detected in a few strains of Aeromonas salmonicida and A. hydrophila (Swift et al. 1997), and Vibrio harveyi has also been shown to produce AHL molecules (Cao \& Meighen 1989). Sterile filtered culture supernatants from the fish pathogens $V$. vulnificus, $V$. splendidus and $V$. salmonicida induce luminescence in $V$. harveyi or $V$. fischeri. Since bioluminescence in these 2 bacteria is controlled by QS, it indicated that the spent culture supernatants contained AHL molecules; however, the structures of these signalling compounds were never elucidated (Greenberg et al. 1979. Fidopiastis et al. 1999). Furthermore in the Enterobacteriaceae, which include a number of fish pathogens, many species have been shown to produce AHL molecules (Temprano et al. 2001, Whitehead et al. 2001). Despite these reports it is not known how widespread AHL production is among fish pathogenic bacteria.

The purpose of the present work was to study how widespread AHL signal molecules are in Gramnegative fish pathogenic bacteria. We therefore assessed the presence of AHLs and tentatively identified the chemical structure by thin-layer chromatography (TLC) and high performance liquid chromatography-high resolution mass spectrometry (HPLC-HR-MS). Subsequently, fish infected with selected fish pathogenic bacteria were tested for the presence of AHLs during infection. If AHLs are produced during growth and if they influence virulence, new disease control methods such as QSI compounds may be used to minimize certain bacterial diseases in aquaculture.

\section{MATERIALS AND METHODS}

Bacterial strains and storage conditions. A selection of important Gram-negative fish pathogenic bacteria were chosen for this study (Table 1). Strains of Aeromonas salmonicida, atypical A. salmonicida, A. hydrophila, Yersinia ruckeri, Vibrio vulnificus and $V$. anguillarum were grown on Brain Heart Infusion (BHI) agar (Oxoid, CM225 with 1.2\% agar). Strains of Photo- 
Table 1. Detection of acylated homoserine lactones (AHLs) by microbiological monitor systems (Agrobacterium tumefaciens NT1 [pZLR4] or Chromobacterium violaceum CV026) from fish pathogenic bacteria. 1: Danish Institute for Fisheries Research/Royal Veterinary and Agricultural University, Copenhagen; 2: University of Iceland; 3: University of Glasgow; 4: National Veterinary Institute in Oslo; 5: Umeå University

\begin{tabular}{|c|c|c|c|c|}
\hline Fish pathogen & $\begin{array}{r}\text { Size } \\
\mathrm{N}\end{array}$ & $\begin{array}{l}\text { of AHL-ind } \\
\Gamma 1 \text { (pZLR4) }\end{array}$ & $\begin{array}{l}\text { zone }(\mathrm{mm}) \\
\text { CV026 }\end{array}$ & Source \\
\hline Aeromonas hydrophila & $\begin{array}{l}\text { ATCC } 7966 \\
92-9-210 \\
96-3-35 \\
90-8-184\end{array}$ & $\begin{array}{l}25 \\
19 \\
30 \\
19\end{array}$ & $\begin{array}{r}<15 \\
16 \\
20 \\
16\end{array}$ & $\begin{array}{l}1 \\
1 \\
1 \\
1\end{array}$ \\
\hline Aeromonas salmonicida & $\begin{array}{l}\text { NCIMB } 1102 \\
02-9-1 \\
02-9-37 \\
93-8-294 \\
94-6-87 \\
219 \\
234\end{array}$ & $\begin{array}{r}<15 \\
18 \\
18 \\
19 \\
19 \\
16 \\
-\end{array}$ & $\begin{array}{r}<15 \\
35 \\
35 \\
35 \\
35 \\
50 \\
<15\end{array}$ & $\begin{array}{l}1 \\
1 \\
1 \\
1 \\
1 \\
2 \\
2\end{array}$ \\
\hline $\begin{array}{l}\text { Atypical } \\
\text { Aeromonas salmonicida }\end{array}$ & $\begin{array}{l}\text { ssp. smithia NCIMB } 13210 \\
\text { ssp. masoucida ATCC } 27013 \\
\text { ssp. pectinolytica DSM } 12609 \\
\text { spp. achromogenes ATCC } 19261 \\
\text { NCIMB } 1110 \\
209 \\
204 \\
183 \\
93 \\
51\end{array}$ & $\begin{array}{l}- \\
- \\
31 \\
- \\
15 \\
- \\
- \\
- \\
- \\
-\end{array}$ & $\begin{array}{l}- \\
- \\
50 \\
- \\
32 \\
- \\
- \\
- \\
- \\
-\end{array}$ & $\begin{array}{l}2 \\
2 \\
2 \\
2 \\
1 \\
2 \\
2 \\
2 \\
2 \\
2\end{array}$ \\
\hline Flavobacterium psychrophilum & $\begin{array}{l}\text { NCIMB } 1947 \\
950106-1 / 1 \\
900406-1 / 3 \\
030514-1 / A 1 A \\
030522-1 / 2\end{array}$ & $\begin{array}{l}- \\
- \\
- \\
- \\
-\end{array}$ & $\begin{array}{l}- \\
- \\
- \\
- \\
-\end{array}$ & $\begin{array}{l}1 \\
1 \\
1 \\
1 \\
1\end{array}$ \\
\hline Moritella viscosa & $\begin{array}{l}\text { F288/95 } \\
\text { F195/94 } \\
\text { F288/95 }\end{array}$ & $\begin{array}{l}- \\
- \\
-\end{array}$ & $\begin{array}{l}- \\
- \\
-\end{array}$ & $\begin{array}{l}2 \\
2 \\
2\end{array}$ \\
\hline Vibrio anguillarum & $\begin{array}{l}\text { NB10 (pos. control) } \\
\text { DM27 (neg. control) }\end{array}$ & $\begin{array}{c}20 \\
-\end{array}$ & $\begin{array}{l}- \\
-\end{array}$ & $\begin{array}{l}5 \\
5\end{array}$ \\
\hline Photobacterium damselae ssp. damselae & $\begin{array}{l}\text { ATCC } 33539 \\
940801-1 / 1 \\
950810-3 / 5 \\
94-11-229 \\
96-2-25 / 1\end{array}$ & $\begin{array}{l}- \\
- \\
- \\
- \\
-\end{array}$ & $\begin{array}{l}- \\
- \\
- \\
- \\
-\end{array}$ & $\begin{array}{l}1 \\
1 \\
1 \\
1 \\
1\end{array}$ \\
\hline Vibrio salmonicida & $\begin{array}{l}\text { NCIMB } 2262 \\
\text { VS81 } \\
\text { VS201 } \\
\text { VS224 } \\
\text { VS288 } \\
\text { VS289 } \\
\text { VS297 } \\
\text { VS399 }\end{array}$ & $\begin{array}{l}40 \\
36 \\
40 \\
38 \\
41 \\
45 \\
38 \\
42\end{array}$ & $\begin{array}{l}25 \\
15 \\
20 \\
16 \\
25 \\
25 \\
18 \\
24\end{array}$ & $\begin{array}{l}4 \\
4 \\
4 \\
4 \\
4 \\
4 \\
4 \\
4\end{array}$ \\
\hline Vibrio splendidus & $\begin{array}{l}\text { DMC-1 } \\
\text { LMS-1 } \\
\text { LTS-3 } \\
\text { LTH-3 } \\
\text { DTC-5 } \\
\text { DTY-1 } \\
\text { NCIMB 1 } \\
\text { NCIMB } 2251\end{array}$ & $\begin{array}{l}16 \\
- \\
- \\
- \\
20 \\
- \\
- \\
-\end{array}$ & $\begin{array}{l}- \\
- \\
- \\
- \\
- \\
- \\
- \\
-\end{array}$ & $\begin{array}{l}3 \\
3 \\
3 \\
3 \\
3 \\
3 \\
3 \\
3\end{array}$ \\
\hline Vibrio vulnificus & $\begin{array}{l}\text { NCIMB } 2136 \\
\text { ATCC } 27562 \\
94-8-108 \\
98-2-32\end{array}$ & $\begin{array}{l}<15 \\
<15 \\
<15 \\
<15\end{array}$ & $\begin{array}{l}- \\
- \\
- \\
-\end{array}$ & $\begin{array}{l}1 \\
1 \\
1 \\
1\end{array}$ \\
\hline Yersinia ruckeri & $\begin{array}{l}\text { NCIMB } 1316 \\
88-6-32 \\
88-6-44 \\
89-4-77 \\
89-5-113\end{array}$ & $\begin{array}{l}>60 \\
>60 \\
>60 \\
>60 \\
>60\end{array}$ & $\begin{array}{r}<15 \\
20 \\
24 \\
19 \\
24\end{array}$ & $\begin{array}{l}1 \\
1 \\
1 \\
1 \\
1\end{array}$ \\
\hline
\end{tabular}


bacterium damselae, V. splendidus and V. salmonicida were grown on Marine Agar (MA) (Difco, 212185). Strains of Flavobacterium psychrophilum were grown on tryptone yeast extract salts agar (TYES agar) (Holt et al. 1993) and strains of Moritella viscosa were grown on Tryptone Soya Agar (TSA) (Oxoid, CM131) with $1.5 \% \mathrm{NaCl}$. A. salmonicida, atypical A. salmonicida, A. hydrophila, Y. ruckeri and V. vulnificus were grown at $25^{\circ} \mathrm{C}$. P. damselae, $V$. splendidus and $M$. viscosa were grown at $20^{\circ} \mathrm{C}$ and $V$. salmonicida and F. psychrophilum were grown at $15^{\circ} \mathrm{C}$. All cultures were stored at $-80^{\circ} \mathrm{C}$ and inoculated onto the respective agar media before further culturing.

Screening for AHL production. A single colony from the relevant agar was transferred to $10 \mathrm{ml}$ of the corresponding broth and incubated as indicated above. Two hundred $\mu \mathrm{l}$ of an outgrown broth culture was plated on the respective agar media and incubated at an appropriate temperature until dense growth covering the agar plate was visible. The agar with colonies was transferred to a glass tube and $15 \mathrm{ml}$ acidified ethylacetate $(0.5 \%$ formic acid) was added. The sample was homogenised using an ultraturex (IKA Labortechnik), and the extract was filtered through a Whatman 4 filter (Whatman, 1004150). The extract was evaporated under nitrogen flow to dryness and reconstituted in $1 \mathrm{ml}$ acidified ethyl-acetate and stored at $-20^{\circ} \mathrm{C}$.

Detection and preliminary characterisation of AHL compounds were performed using the 2 AHL monitor bacteria Agrobacterium tumefaciens NT1 (pZLR4) (Cha et al. 1998) and Chromobacterium violaceum
CV026 (Throup et al. 1995, McClean et al. 1997). These monitor bacteria are used in agar-based monitor systems to demonstrate the presence of AHL, since they do not themselves produce AHL compounds, but the bacteria respond to the presence of AHL compounds by inducing phenotypes, which results in colour changes in the surrounding agar (Fig. 1). The colour change in $A$. tumefaciens NT1 (pZLR4) is caused by AHL-induction of $\beta$-galactocidase which will break down the X-Gal which is added to the agar; this results in the blue colour. In C. violaceum CV026, AHLs induce production of the purple compound violacein. The 2 bacteria differ in the spectrum of AHL compounds to which they respond, since $A$. tumefaciens NT1 (pZLR4) is known to be most sensitive to 3oxo-AHLs whereas C. violaceum CV026 is most sensitive to AHLs with between 4 and 8 carbon atoms and no substitutions on the 3rd carbon atom of the acyl chain. All extracts were tested in a well diffusion assay (Ravn et al. 2001) with the 2 monitor bacteria to determine the presence of AHL compounds. All positive samples were profiled by using reverse phase $\mathrm{C}_{18}$ TLC, which separated the AHL compounds present in the sample, and then by overlaying the TLC plate with agar supplemented with one of the abovementioned monitor bacteria (Shaw et al. 1997, Ravn et al. 2001). The different AHL compounds have a characteristic migration length in the TLC plate called the retention factor $\left(R_{\mathrm{f}}\right)$. Spots of induction in the overlaying agar can therefore be characterised by an $R_{\mathrm{f}}$ value, which can be compared to synthetic AHL standards. A repre-
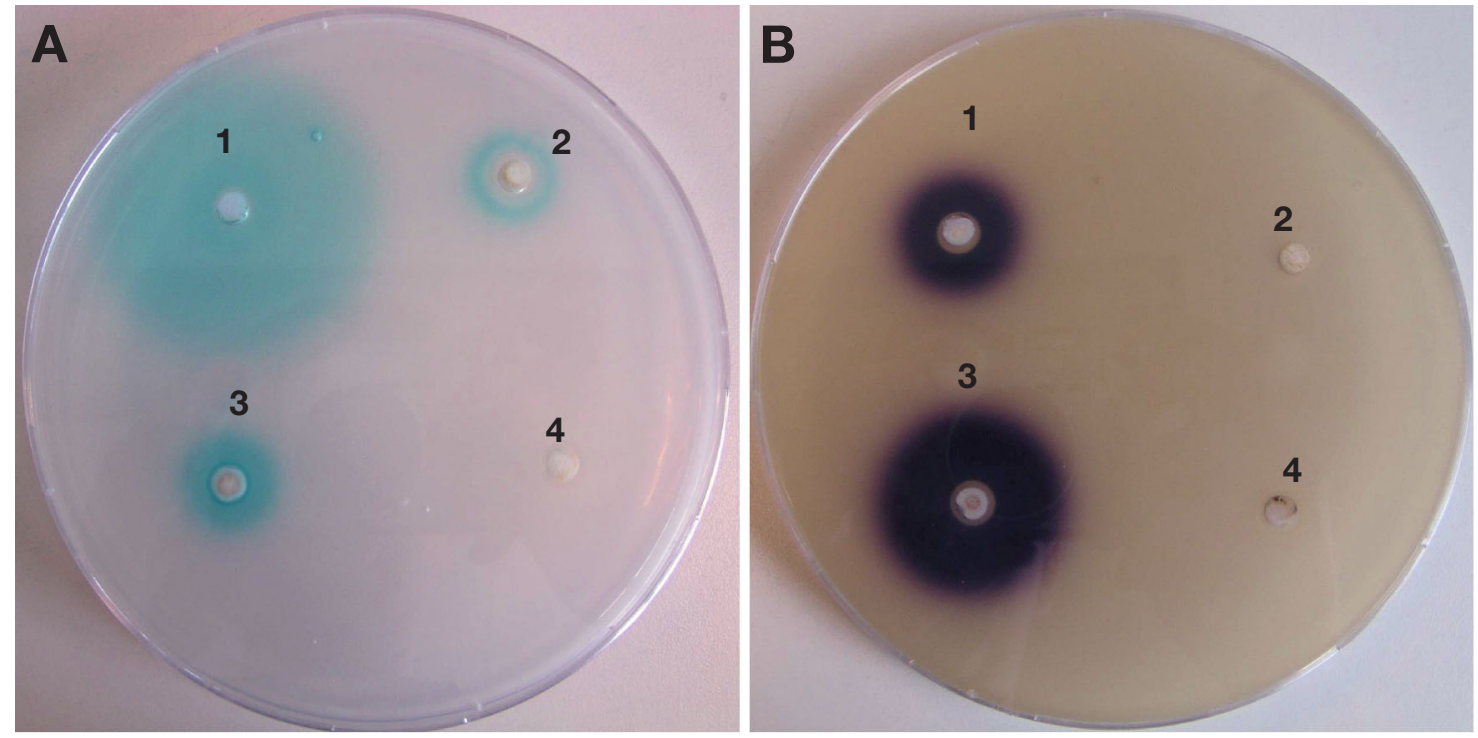

Fig. 1. Extracts from (1) Yersinia ruckeri 88-6-44 grown on agar, (2) trout infected with Yersinia ruckeri 88-6-44, (3) Aeromonas salmonicida 02-9-37 grown on agar and (4) trout infected with A. salmonicida 02-9-37. (A) Induction of $\beta$-galactosidase in an X-Gal containing medium by the AHL monitor, Agrobacterium tumefaciens NT1 (pZLR4). (B) Induction of violacein by the AHL monitor Chromobacterium violaceum CV026 in a well diffusion assay 
sentative subset of samples was further characterised with HPLC-HR-MS as described below. The following reference standards were available: $N$-butanoyl homoserine lactone (BHL), $N$-hexanoyl homoserine lactone (HHL), N-3-octanoyl homoserine lactone (OHL), $N$ decanoyl homoserine lactone (DHL), $N$-dodecanoyl homoserine lactone (dDHL), $N$-tetradecanoyl homoserine lactone (tDHL), $N$-3-oxo-hexanoyl homoserine lactone (OHHL) and N-3-oxo-octanoyl homoserine lactone (OOHL).

HPLC-HR-MS analysis. Ethyl acetate extracts were evaporated in vacuo, redissolved in $100 \mu \mathrm{l}$ methanolwater (1:1), filtered through a $0.45 \mu \mathrm{m}$ Teflon syringe filter and analysed by high performance liquid chromatography-positive ionization electrospray highresolution mass spectrometry (HPLC-HR-MS) on an LCT orthogonal Time Of Flight mass spectrometer (Micromass) as described by Nielsen \& Smedsgaard (2003). Chromatographic separation was performed on a Phenomenex (Torrance) Luna II $\mathrm{C}_{18}$ (II), $3 \mu \mathrm{m}, 50 \times$
$2 \mathrm{~mm}$ column with a pre-column, using a gradient system of water (Milli-Q) containing $10 \mathrm{mM}$ ammonium formiate and $20 \mathrm{mM}$ formic acid (both analytical grade) and acetonitril (AcN) (gradient grade) containing $20 \mathrm{mM}$ formic acid. A flow of $0.3 \mathrm{ml} \mathrm{min}{ }^{-1}$ was used, starting with $5 \%$ AcN for 2 min, which was increased linearly to $100 \%$ AcN in $18 \mathrm{~min}$ and held for $5 \mathrm{~min}$ at this level, before returning to $5 \% \mathrm{AcN}$ in $4 \mathrm{~min}$, and then equilibrated for $7 \mathrm{~min}$. In positive electrospray ionization $\left(\mathrm{ESI}^{+}\right)$the target molecules are intended to be ionized by addition of a proton to the molecules forming the $[\mathrm{M}+\mathrm{H}]^{+}$complex which can then be measured in the mass spectrometer. However, some of the target molecules (depending largely on the compound) will be attached to a sodium ion instead (even though using ultra-pure solvents), and some molecules can also be clusters with the solvent, in this case $\mathrm{AcN}$, forming $\left[\mathrm{M}+\mathrm{Na}+\mathrm{CH}_{3} \mathrm{CN}^{+}\right.$, thus giving the $\mathrm{ESI}^{+}$ spectrum shown in Fig. 2. High resolution means that the mass to charge ratio $(\mathrm{m} / \mathrm{z})$ can be measured very

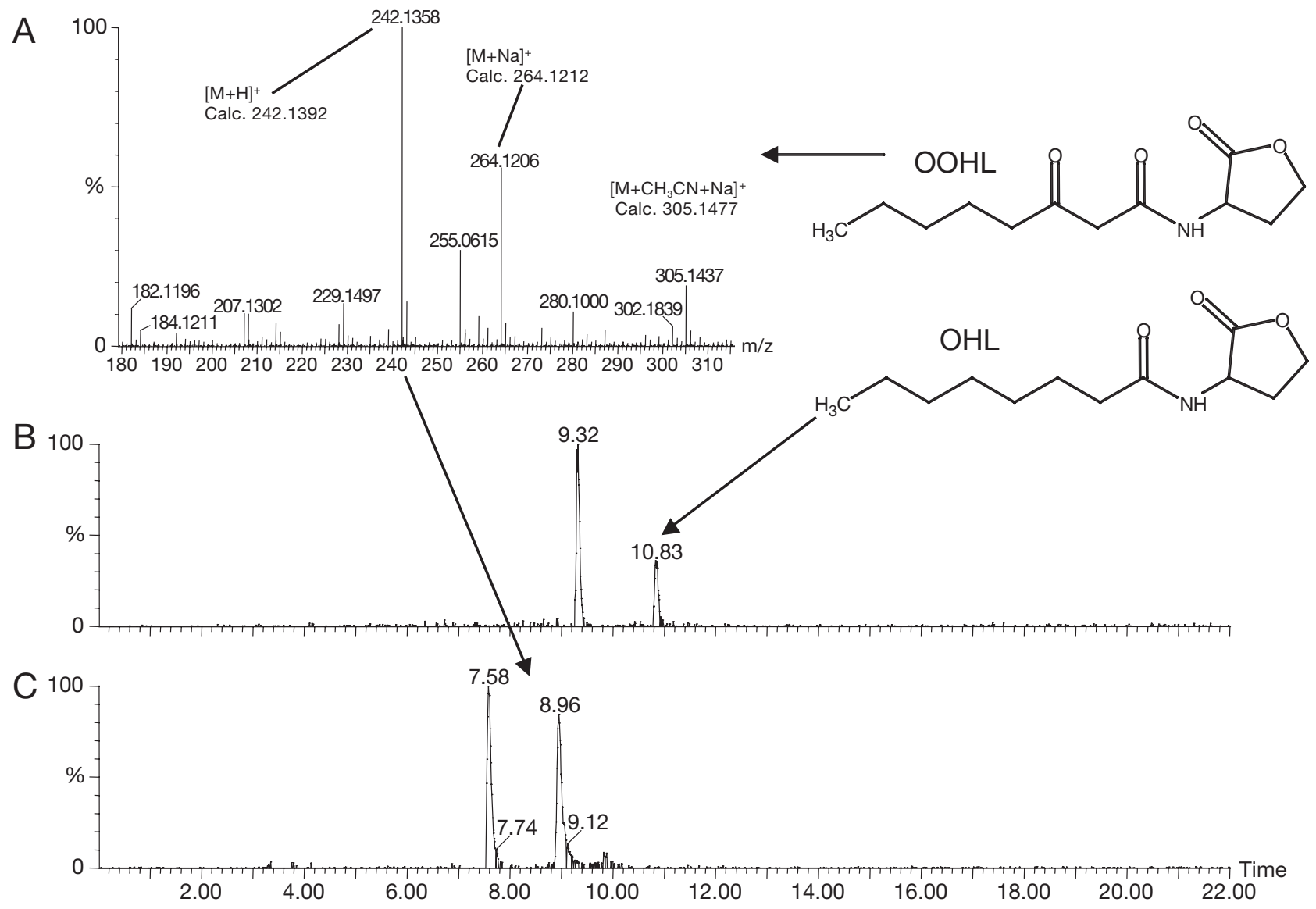

Fig. 2. Liquid chromatography - positive electrospray ionization $\left(\mathrm{ESI}^{+}\right)$mass spectrometry chromatograms of extracts of Yersinia ruckeri strain 88-6-44. (A) ESI ${ }^{+}$spectrum of $N$-3-oxo-octanoyl homoserine lactone (OOHL) with the calculated masses for the predominant adducts. (B) Extracted ion chromatogram (m/z 228.154 to 228.170) showing N-3-octanoyl homoserine lactone (OHL) at 10.83 min. (C) Extracted ion chromatograms (m/z 242.135 to 242.144) showing the protonated, [M+H] ${ }^{+}$adducts of OOHL at $8.96 \mathrm{~min}$ 
accurately so that, e.g., the $[\mathrm{M}+\mathrm{H}]^{+}$ion of OOHL $\left(\mathrm{C}_{12} \mathrm{H}_{22} \mathrm{NO}_{4}\right)$ with a theoretical $\mathrm{m} / \mathrm{z}$ of 244.1549 can be differentiated from an ion of the same nominal mass as $\mathrm{C}_{16} \mathrm{H}_{22} \mathrm{NO}$ which has an $\mathrm{m} / \mathrm{z}$ of 244.1701. On new Time Of Flight instruments a precision of ca. $\pm 0.006 \mathrm{~m} / \mathrm{z}$ or better can be obtained, whereas the much more common quadruple and ion-trap mass spectrometers have a precision of $\pm 0.2 \mathrm{~m} / \mathrm{z}$ or worse.

Experimental infection. Rainbow trout Oncorhynchus mykiss with an average weight of $59 \mathrm{~g}$ were used. The fish were kept in 161 capacity tanks with aerated static freshwater at 9 to $10^{\circ} \mathrm{C}$. The water was changed daily. The fish were fed a commercial feed according to appetite throughout the experiment. Five fish were challenged by intraperitoneal injection of $0.1 \mathrm{ml}$ of an exponential-phase culture (approximately $10^{8} \mathrm{cfu} \mathrm{ml}^{-1}$ ) of Yersinia ruckeri strain 88-6-44 and 5 fish with Aeromonas salmonicida strain 02-9-37 which were grown in Veal Infusion broth (Difco [BD], 234420) overnight at $20^{\circ} \mathrm{C}$. The fish were observed for $10 \mathrm{~d}$ and dead and moribund fish were collected and samples from kidney, spleen and brain were cultured on Blood Agar base (BA) (Oxoid, CM55; with 5\% citrated calf blood). The identities of isolated bacteria were confirmed by standard biochemical tests and serotyping. Surviving fish and 4 control fish (not infected) were sacrificed at the end of the experiment and examined in a similar manner. The organs from both infected and control fish were analysed for AHLs by homogenising the organs in acidified ethyl acetate $\left(1 \mathrm{ml} \mathrm{g}^{-1}\right)$ in an ultraturrex. After filtration and drying, as described above, the samples were re-dissolved in $1 \mathrm{ml}$ ethyl acetate, and the samples were tested in a well diffusion assay with the monitor bacteria Agrobacterium tumefaciens NT1 (pZLR4) and Chromobacterium violaceum CV026 and positive extracts were characterised by TLC, and HPLCHR-MS.

\section{RESULTS}

\section{Detection of AHL in fish pathogenic bacteria}

To determine if a collection of fish pathogenic bacteria produced AHL molecules, we tested the bacteria listed in Table 1 in a well diffusion assay with the 2 AHL monitor bacteria Agrobacterium tumefaciens NT1 (pZLR4) and Chromobacterium violaceum CV026. All strains of Aeromonas hydrophila, Aeromonas salmonicida, Vibrio salmonicida, V. vulnificus and Yersinia ruckeri induced at least 1 of the 2 monitor bacteria. Also 2 atypical Aeromonas salmonicida (ssp. pectinolytica and NCIMB 1110) and 2 strains of $V$. splendidus (DMC1 and DTC5) induced the monitor bacteria. No induction was detected from the remaining strains of atypical A. salmonicida and $V$. splendidus. When testing extracts from Flavobacterium psychrophilum, Photobacterium damselae and Moritella viscosa no AHL induction was detected. The AHL producing $V$. anguillarum (NB10) strain and an AHL-negative mutant $V$. anguillarum (DM27) strain were used as positive and negative controls (Milton et al. 2001).

As evident from Table 1, the zones of AHL induction were, in general, similar in size within each bacterial species, thus indicating similar AHL production. However Aeromonas salmonicida strains NCIMB 1102, 219 and 234 were unlike the other $A$. salmonicida strains. When comparing the induction zones in the well diffusion assay one has to keep in mind the fact that the zones cannot be used directly as a quantitative measure of the presence of AHL in a sample, since the sensitivity of the monitor bacteria differ for the different AHL molecules, e.g. Agrobacterium tumefaciens NT1 (pZLR4) is known to be most sensitive for 3-oxoAHLs whereas Chromobacterium violaceum CV026 is most sensitive to AHLs with between 4 and 8 carbon atoms.

\section{Characterisation of AHL}

To characterise the AHL molecules produced, TLC was performed with the 2 monitor bacteria, and selected samples from each fish pathogen were analysed with HPLC-HR-MS (Fig. 2). The TLC profiles demonstrated that in strains of Aeromonas hydrophila, A. salmonicida, Vibrio salmonicida and Yersinia ruckeri more than 1 AHL molecule was produced by all bacterial species, and within each species similar TLC profiles were found (data not shown). HPLC-HR-MS confirmed the results found with TLC; however, only some of the spots detected by TLC were detected with the HPLC-HR-MS analysis (Table 2), probably due to differences in sensitivity of the 2 methods.

Two strains of Aeromonas salmonicida and 1 strain of A. hydrophila had almost identical TLC profiles, including 3 different compounds, 1 of which had a shape and $R_{\mathrm{f}}$ value similar to $N$-butanoyl homoserine lactone (BHL), 1 to $N$-hexanoyl homoserine lactone (HHL), and 1 unidentified compound was also present. No TLC profile could be obtained from A. hydrophila ATCC 7966. HPLC-HR-MS analysis not only revealed production of BHL in all of the 4 Aeromonas strains tested (Table 2) but also detected $N$-decanoyl homoserine lactone (DHL), $N$-3-oxo-hexanoyl homoserine lactone (OHHL) and HHL in extracts from A. salmonicida 02-9-1. Strains of Yersinia ruckeri produced TLC profiles which had an indication of $\mathrm{N}$-3-oxo-octanoyl homoserine lactone (OOHL) and $N$-octanoyl homoserine lactone (OHL) production which was confirmed by 
Table 2. Types of acylated homoserine lactones produced by fish pathogenic bacteria as determined by thin layer chromatography (using Agrobacterium tumefaciens NT1 [pZLR4] or Chromobacterium violaceum CV026) or high performance liquid chromatography-high resolution mass spectometry (HPLC-HR-MS). ni: not identified

\begin{tabular}{|c|c|c|c|c|}
\hline Fish pathogen & Strain & $\begin{array}{l}\text { Tentative ide } \\
\text { NT1 (pZLR4) }\end{array}$ & $\begin{array}{l}\text { of AHL with } \\
\text { CV026 }\end{array}$ & HPLC-HR-MS \\
\hline Aeromonas hydrophila & $\begin{array}{l}\text { ATCC } 7966 \\
96-3-35\end{array}$ & $\begin{array}{l}\text { ni } \\
\text { ni }\end{array}$ & $\begin{array}{c}\text { ni } \\
\mathrm{BHL}, \mathrm{HHL}^{\mathrm{a}}\end{array}$ & $\begin{array}{l}\text { BHL } \\
\text { BHL }\end{array}$ \\
\hline Aeromonas salmonicida & $\begin{array}{l}\text { NCIMB } 1110 \\
02-9-1\end{array}$ & $\begin{array}{l}\text { ni } \\
\text { ni }\end{array}$ & $\begin{array}{l}\text { BHL, } \text { HHL }^{a} \\
\text { BHL, HHL }\end{array}$ & $\begin{array}{c}\text { BHL } \\
\text { BHL, DHL, HHL, OHHL }\end{array}$ \\
\hline Yersinia ruckeri & $\begin{array}{l}\text { NCIMB } 1316 \\
88-6-44\end{array}$ & $\begin{array}{l}\text { OOHL, OHL } \\
\text { OOHL, OHL }\end{array}$ & $\begin{array}{l}\text { OOHL, OHL } \\
\text { OOHL, OHL }\end{array}$ & $\begin{array}{l}\text { OOHL, OHL } \\
\text { OOHL, OHL }\end{array}$ \\
\hline Vibrio salmonicida & $\begin{array}{l}\text { NCIMB } 2262 \\
289\end{array}$ & $\begin{array}{l}\text { OHHL, HHL } \\
\text { OHHL, HHL }\end{array}$ & $\begin{array}{l}\text { HHL } \\
\text { HHL }\end{array}$ & $\begin{array}{l}\text { OHHL, HHL } \\
\text { OHHL, HHL }\end{array}$ \\
\hline Vibrio splendidus & $\begin{array}{l}\text { DTC-5 } \\
\text { DMC-1 }\end{array}$ & $\begin{array}{l}\text { ni } \\
\text { ni }\end{array}$ & $\begin{array}{l}\mathrm{ni} \\
\mathrm{ni}\end{array}$ & $\begin{array}{l}\text { ni } \\
\text { ni }\end{array}$ \\
\hline Vibrio vulnificus & $\begin{array}{l}\text { ATCC } 27562 \\
98-2-32\end{array}$ & $\begin{array}{l}\text { ni } \\
\text { ni }\end{array}$ & $\begin{array}{l}\text { ni } \\
\text { ni }\end{array}$ & $\begin{array}{l}\text { ni } \\
\text { ni }\end{array}$ \\
\hline
\end{tabular}

HPLC-HR-MS (Fig. 2, Table 2). Both the TLC profiles and the HPLC-HR-MS analysis from extracts of Vibrio salmonicida detected OHHL and HHL. No TLC profiles could be obtained and no molecules were detected with HPLC-HR-MS in strains of $V$. vulnificus or in strains DMC-1 and DTC-5 of V. splendidus even though induction in Agrobacterium tumefaciens NT1 (pZLR4) was detected in the well diffusion assay.

\section{Infection experiment}

Infection experiments were performed with Aeromonas salmonicida 02-9-37 and Yersinia ruckeri 88-644 to investigate whether AHLs were produced during infection of fish. Dead and moribund fish showed haemorrhages in the internal organs. All extracts of organs from the 5 fish (3 moribund, 2 dead) infected with Y. ruckeri 88-6-44 induced Agrobacterium tumefaciens NT1 (pZLR4) in a well diffusion assay (Table 3, Fig. 1) but no induction was seen in Chromobacterium violaceum CV026. No extracts from the 5 fish (2 moribund, 1 dead, 2 sacrificed) infected with $A$. salmonicida 02-09-37 (Fig. 1) or noninfected control fish induced the monitor bacteria. Extracts from fish infected with Y. ruckeri 88-6-44 were analysed using TLC and 1 fish sample was also investigated by HPLC-HR-MS. The TLC profiles with $A$. tumefaciens NT1 (pZLR4) were identical with the profile obtained from pure culture and indicated presence of OOHL and OHL
(Table 3). No AHL compounds were detected in the fish extracts with HPLC-HR-MS, possibly as a result of interfering substances acting to depress the ionization of OOHL and OHL, a well known problem for electrospray ionization, which has only a limited supply of charges per time. Another reason could be that $A$. tumefaciens NT1 (pZLR4) is more sensitive to OOHL than the LC-HR-MS. A. salmonicida and Y. ruckeri were isolated in pure culture from the infected fish, and extracts made from these agar plates induced the AHL monitor bacteria.

\section{DISCUSSION}

The present study demonstrates that communication signals which typically are involved in QS among Gram-negative bacteria are produced by several spe-

Table 3. Induction of AHL-monitor bacteria, Agrobacterium tumefaciens NT1 (pZLR4), by extracts from trout infected with Aeromonas salmonicida or Yersinia ruckeri. ni: no induction

\begin{tabular}{|lccc|}
\hline Fish infected with & Fish no. & $\begin{array}{c}\text { Size of AHL-induction } \\
\text { zone (mm) } \\
\text { NT 1(pZLR4) }\end{array}$ & $\begin{array}{c}\text { Tentative ID } \\
\text { on TLC } \\
\text { NT1 (pZLR4) }\end{array}$ \\
\hline Aeromonas salmonicida & 1 & $\mathrm{ni}$ & - \\
$02-9-37$ & 2 & $\mathrm{ni}$ & - \\
& 3 & $\mathrm{ni}$ & - \\
& 4 & $\mathrm{ni}$ & - \\
Yersinia ruckeri & 5 & $\mathrm{ni}$ & $\mathrm{ni}$ \\
88-6-44 & 1 & 17 & OOHL + OHL \\
& 2 & 25 & OOHL + OHL \\
& 3 & 34 & ni \\
& 4 & 16 & OOHL + OHL \\
\hline
\end{tabular}


cies of fish pathogenic bacteria. Other studies have also detected production of AHLs in fish pathogenic bacteria (Cao \& Meighen 1989, Swift et al. 1997, Milton et al. 2001, Temprano et al. 2001, Buch et al. 2003) but have typically worked with 1 or only a few strains. As evident from Table 1, it appears that if a species produces AHLs, then this is a common trait in several strains belonging to this species. However, only 2 strains of Vibrio splendidus (DMC-1 and DTC-5) and 2 strains of atypical Aeromonas salmonicida (ssp. pectinolytica and NCIMB 1110) induced at least 1 of the monitor bacteria, whereas the remaining $V$. splendidus and atypical $A$. salmonicida strains did not induce any of the monitor bacteria.

Apart from one study (Buch et al. 2003), others have exclusively worked in laboratory media and settings but not addressed AHL production during bacterial infection (Swift et al. 1997, Milton et al. 2001, Temprano et al. 2001). If AHLs are involved in regulating the expression of virulence-related genes then clearly they must be present in the fish during infection. We detected AHLs during infection of rainbow trout with Yersinia ruckeri, suggesting an involvement in the infection. However, based on the induction zone, the concentration was less than when grown in laboratory media (>60 $\mathrm{mm}$ zone from agar extracts versus $25 \mathrm{~mm}$ zones from infected fish). Proof of the involvement of AHLs in infection requires that inhibiting AHLs would halt the progression of the infection.

AHLs could not be detected from fish infected with Aeromonas salmonicida. This could be either because the compounds were not produced (and not involved in virulence) or because the concentrations were below the sensitivity of the monitor detection systems that were used.

Based on TLC profiling we found that BHL and HHL and one additional molecule were produced by Aeromonas species as previously reported (Swift et al. 1997). The microbiological AHL monitors have a 'bias' in terms of the AHLs they detect which is dependent on receptor specificity (McClean et al. 1997, Shaw et al. 1997) and so careful interpretation of data regarding the lack or dominance of particular AHLs is required. Therefore, it is important to verify the AHL profile by chemical analysis. HPLC-HR-MS showed BHL as the dominant molecule in the Aeromonas strains but also, in 1 strain, detected HHL and 2 additional compounds which were not visualised by the TLC procedure.

Fidopiastis et al. (1999) found that spent medium of Vibrio salmonicida led to an induction of the QSregulated phenotype, bioluminescence, in $V$. fischeri, indicating that $V$. salmonicida produced an AHL, which was subsequently identified as OHHL. We did indeed detect OHHL but also HHL in all tested $V$. salmonicida strains. V. salmonicida is closely related to $V$. fischeri in which AHL regulation was first discovered (Nealson et al. 1970). OHHL is the major AHL molecule in $V$. fischeri and it regulates bioluminescence (Eberhard et al. 1981). Fidopiastis et al. (1999) detected OHHLinduced bioluminescence in a culture of $V$. salmonicida. In contrast, we could not visually detect bioluminescence in any of the tested strains with or without addition of $10 \mu \mathrm{M}$ OHHL (data not shown). Although our strains are different from that used by Fidopiastis et al. (1999), it seems unusual that a phenotype which the organism does not naturally express can be activated by an overload of particular signal molecules, which are produced by the bacterium itself. In any case, bioluminescence does not appear to be a phenotype of relevance for pathogenecity of the bacteria.

Temprano et al. (2001) used Chromobacterium violaceum CV026 to isolate the AHL synthetase gene yruI in Yersinia ruckeri but the structure of the signal molecule(s) was never elucidated. In the present study we found induction in both $C$. violaceum $\mathrm{CV} 026$ and Agrobacterium tumefaciens NT1 (pZLR4), and TLC and HPLC-HR-MS demonstrated that the organism produced OOHL and OHL. OOHL is also produced by the plant pathogen $A$. tumefaciens in which it plays a key role in regulating the expression of a virulence phenotype (Pierson et al. 1998). OHL is produced by $V$. fischeri in which the compound, at low cell densities, inhibits bioluminescence (Kuo et al. 1996).

AHLs were extracted from fish challenged with Yersinia ruckeri and whilst this in not proof of their involvement in pathogenicity, it indicates that a QS system is active during infection. Phenotypes which are likely to be QS-regulated in Y. ruckeri are the metalloprotease and a protein secretion system which both play an important role in the pathogenicity of this bacterium (Fernandez et al. 2002). It has been demonstrated that metalloproteases and exporter proteins are regulated by a QS system in other bacteria (Croxatto et al. 2002, Christensen et al. 2003).

Small zones of presumed AHL induction were detected from Vibrio vulnificus (Table 1); however, no AHL $\mathrm{s}$ were detected by TLC or HPLC-HR-MS. Kim et al. (2003) did not detect AHL in strains of $V$. vulnificus but did detect the signal molecule AI2 and this molecule was involved in expression of virulence factors. AI2 is a boron containing furanone which is involved in the QS regulation of bioluminescence in $V$. harveyi (Chen et al. 2002). Compounds other than AHLs, such as di-ketopiperazines, may induce a weak AHL reaction in the Agrobacterium tumefaciens NT1 (pZLR4) and Chromobacterium violaceum CV026 (Holden et al. 1999, Degrassi et al. 2002). We found that small zones of AHL induction were detected by A. tumefaciens NT1 (pZLR4) in 2 strains of $V$. splendidus but none 
were detected with either TLC or HPLC-HR-MS. Hence, it is likely that either the strains do not produce AHL molecules but other molecules which induce A. tumefaciens (e.g. di-ketopiperazines) or the strains produce low concentrations of AHL molecules which must be concentrated and purified before detection with TLC and/or HPLC-HR-MS.

AHLs were not detected by the monitor bacteria used in various strains of Flavobacterium psychrophilum, Moritella viscosa, and Photobacterium damselae. The combined use of Agrobacterium tumefaciens NT1 (pZLR4) and Chromobacterium violaceum CV026 does allow for the detection of most known AHLs (Ravn et al. 2001). However, QS signals not detected by these monitors could be present in the presumed negative species. These bacteria may have the ability to perform QS by using other molecules, e.g. AI2 (Surette et al. 1999), or they may not produce the AHL molecules themselves but express the receptor protein (Ahmer et al. 1998) and thereby sense other AHL-producing bacteria.

If QS systems are involved in regulating the expression of virulence factors, the long-term practical application in aquaculture could be the use of QSI compounds as a non-antibiotic based treatment of bacterial infections (Rasch et al. 2004). The advantage of such an approach is that the development of resistant bacteria is avoided, since the virulence of the bacteria is specifically blocked and growth not inhibited. AHLs do not only regulate virulence expression in bacteria but may also modulate the host immune response. For instance, cytokine production decreased and antibody production was inhibited in murine and human leucocytes in the presence of $\mathrm{N}$-3-oxo-dodecanoyl homoserine lactone (OdDHL) (Telford et al. 1998). Hence, one may speculate that QSI compounds may also interact directly with the host (fish). Indeed, QSI compounds reduced the accumulated mortality during an infection experiment with Vibrio anguillarum (Rasch et al. 2004). However, the same level of mortality was reached when trout were infected with an AHL-negative mutant and with a wildtype strain of $V$. anguillarum (Croxatto et al. 2002), suggesting that QSI compounds could exert their effect by interacting directly with the fish.

Acknowledgements. This work was financed by the Danish Research Council for the Technical Sciences under the project 'A new approach to the control of microbial activity' and the research network SCOFDA (Sustainable Control of Fish Diseases in Aquaculture) supported by the Danish Agricultural and Veterinary Research Council and the Danish Ministry of Food, Agriculture and Fisheries. We thank Professor Harry Birkbeck, Glasgow University, Professor Henning Sørum, National Veterinary Institute in Oslo, Dr. Debra Milton, Umeå University, and Gísli Jónsson, University of Iceland, for their donations of bacterial strains.

\section{LITERATURE CITED}

Ahmer BMM, van Reeuwijk J, Timmers CD, Valentine PJ, Heffron F (1998) Salmonella typhimurium encodes an SdiA homolog, a putative quorum sensor of the LuxR family, that regulates genes on the virulence plasmid. J Bacteriol 180:1185-1193

Buch C, Sigh J, Nielsen J, Larsen JL, Gram L (2003) Production of acylated homoserine lactones by different serotypes of Vibrio anguillarum both in culture and during infection of rainbow trout. Syst Appl Microbiol 26:338-349

Cao JG, Meighen EA (1989) Purification and structural identification of an autoinducer for the luminescence system of Vibrio harveyi. J Biol Chem 264:21670-21676

Cha C, Gao P, Chen YC, Shaw PD, Farrand SK (1998) Production of acyl-homoserine lactone quorum-sensing signals by gram-negative plant-associated bacteria. Mol PlantMicrobe Interact 11:1119-1129

Chen X, Schauder S, Potier N, Van Dorsselaer A, Pelczer I, Bassler BL, Hughson FM (2002) Structural identification of a bacterial quorum-sensing signal containing boron. Nature 415:545-549

Christensen AB, Riedel K, Eberl L, Flodgaard LR, Molin S, Gram L, Givskov M (2003) Quorum-sensing-directed protein expression in Serratia proteamaculans B5a. Microbiology 149:471-483

Croxatto A, Chalker VJ, Lauritz J, Jass J, Hardman A, Williams P, Camara M, Milton DL (2002) VanT, a homologue of Vibrio harveyi LuxR, regulates serine, metalloprotease, pigment, and biofilm production in Vibrio anguillarum. J Bacteriol 184:1617-1629

Degrassi G, Aguilar C, Bosco M, Zahariev S, Pongor S, Venturi V (2002) Plant growth-promoting Pseudomonas putida WCS358 produces and secretes 4 cyclic dipeptides: cross-talk with quorum sensing bacterial sensors. Curr Microbiol 45:250-254

de Kievit TR, Iglewski BH (2000) Bacterial quorum sensing in pathogenic relationships. Infect Immun 68:4839-4849

DePaola A, Peeler JT, Rodrick GE (1995) Effect of oxytetracycline-medicated feed on antibiotic-resistance of Gramnegative bacteria in catfish ponds. Appl Environ Microbiol 61:2335-2340

Eberhard A, Burlingame AL, Eberhard C, Kenyon GL, Nealson KH, Oppenheimer NJ (1981) Structural identification of autoinducer of Photobacterium fischeri luciferase. Biochemistry 20:2444-2449

Eberl L (1999) N-acyl homoserinelactone-mediated gene regulation in gram-negative bacteria. Syst Appl Microbiol 22:493-506

Fernandez L, Secades P, Lopez JR, Marquez I, Guijarro JA (2002) Isolation and analysis of a protease gene with an ABC transport system in the fish pathogen Yersinia ruckeri: insertional mutagenesis and involvement in virulence. Microbiology 148:2233-2243

Fidopiastis PM, Sorum H, Ruby EG (1999) Cryptic luminescence in the cold-water fish pathogen Vibrio salmonicida. Arch Microbiol 171:205-209

Freeman JA, Bassler BL (1999) A genetic analysis of the function of LuxO, a 2-component response regulator involved in quorum sensing in Vibrio harveyi. Mol Microbiol 31: 665-677

Givskov M, De Nys R, Manefield M, Gram L and 5 others (1996) Eukaryotic interference with homoserine lactonemediated prokaryotic signaling. J Bacteriol 178:6618-6622

Greenberg EP, Hastings JW, Ulitzur S (1979) Induction of luciferase synthesis in Beneckea harveyi by other marinebacteria. Arch Microbiol 120:87-91 
Hentzer M, Wu H, Andersen JB, Riedel K and 14 others (2003) Attenuation of Pseudomonas aeruginosa virulence by quorum sensing inhibitors. EMBO J 22:3803-3815

Holden MTG, Chhabra SR, De Nys R, Stead P and 13 others (1999) Quorum-sensing cross talk: isolation and chemical characterization of cyclic dipeptides from Pseudomonas aeruginosa and other Gram-negative bacteria. Mol Microbiol 33:1254-1266

Holt RA, Rohavec JS, Fryer JL (1993) Bacterial coldwater disease. In: Inglis V, Roberts RJ, Bromage NR (eds) Bacterial diseases of fish. Blackwell Scientific Publications, Oxford, p 3-23

Jones S, Yu B, Bainton NJ, Birdsall M and 10 others (1993) The lux autoinducer regulates the production of exoenzyme virulence determinants in Erwinia carotovora and Pseudomonas aeruginosa. EMBO J 12:2477-2482

Kim SY, Lee SE, Kim YR, Kim CM, Ryu PY, Choy HE, Chung SS, Rhee JH (2003) Regulation of Vibrio vulnificus virulence by the LuxS quorum-sensing system. Mol Microbiol 48:1647-1664

Kuo A, Callahan SM, Dunlap PV (1996) Modulation of luminescence operon expression by N-octanoyl-L-homoserine lactone in ainS mutants of Vibrio fischeri. J Bacteriol 178: 971-976

Manefield M, Harris L, Rice SA, De Nys R, Kjelleberg S (2000) Inhibition of luminescence and virulence in the black tiger prawn (Penaeus monodon) pathogen Vibrio harveyi by intercellular signal antagonists. Appl Environ Microbiol 66:2079-2084

Manefield M, Welch M, Givskov M, Salmond GPC, Kjelleberg $S$ (2001) Halogenated furanones from the red alga, Delisea pulchra, inhibit carbapenem antibiotic synthesis and exoenzyme virulence factor production in the phytopathogen Erwinia carotovora. FEMS Microbiol Lett 205: 131-138

McClean KH, Winson MK, Fish L, Taylor A and 8 others (1997) Quorum sensing and Chromobacterium violaceum: exploitation of violacein production and inhibition for the detection of $N$-acylhomoserine lactones. Microbiology 143: 3703-3711

Milton DL, Chalker VJ, Kirke D, Hardman A, Camara M, Williams P (2001) The luxM Homologue vanM from Vibrio anguillarum directs the synthesis of $\mathrm{N}$-(3-hydroxyhexanoyl) homoserine lactone and $N$-hexanoylhomoserine lactone. J Bacteriol 183:3537-3547

Nealson KH, Platt T, Hastings JW (1970) Cellular control of synthesis and activity of bacterial luminescent system. J Bacteriol 104:323-330

Nielsen KF, Smedsgaard J (2003) Fungal metabolite screening: database of 474 mycotoxins and fungal metabolites for dereplication by standardised liquid chromatographyUV-mass spectrometry methodology. J Chromatogr A 1002: 111-136

Pierson LS, Wood DW, Pierson EA (1998) Homoserine lactonemediated gene regulation in plant-associated bacteria. Annu Rev Phytopathol 36:207-225

Editorial responsibility: David Bruno, Aberdeen, UK
Rasch M, Buch C, Austin B, Slierendrecht WJ and 7 others (2004) An inhibitor of bacterial quorum sensing reduces mortalities caused by vibriosis in rainbow trout (Oncorhynchus mykiss, Walbaum). Syst Appl Microbiol 27: 350-359

Ravn L, Christensen AB, Molin S, Givskov M, Gram L (2001) Methods for detecting acylated homoserine lactones produced by Gram-negative bacteria and their application in studies of AHL-production kinetics. J Microbiol Methods 44:239-251

Schmidt AS, Bruun MS, Dalsgaard I, Pedersen K, Larsen JL (2000) Occurrence of antimicrobial resistance in fishpathogenic and environmental bacteria associated with four Danish rainbow trout farms. Appl Environ Microbiol 66:4908-4915

Shaw PD, Ping G, Daly SL, Cha C, Cronan JE, Rinehart KL, Farrand SK (1997) Detecting and characterizing $N$-acylhomoserine lactone signal molecules by thin-layer chromatography. Proc Natl Acad Sci USA 94:6036-6041

Surette MG, Miller MB, Bassler BL (1999) Quorum sensing in Escherichia coli, Salmonella typhimurium, and Vibrio harveyi: a new family of genes responsible for autoinducer production. Proc Natl Acad Sci USA 96:1639-1644

Swift S, Karlyshev AV, Fish L, Durant EL and 5 others (1997) Quorum sensing in Aeromonas hydrophila and Aeromonas salmonicida: identification of the LuxRI homologs AhyRI and AsaRI and their cognate $N$-acylhomoserine lactone signal molecules. J Bacteriol 179:5271-5281

Swift S, Lynch MJ, Fish L, Kirke DF, Tomas JM, Stewart GSAB, Williams P (1999) Quorum sensing-dependent regulation and blockade of exoprotease production in Aeromonas hydrophila. Infect Immun 67:5192-5199

Telford G, Wheeler D, Williams P, Tomkins PT and 5 others (1998) The Pseudomonas aeruginosa quorum-sensing signal molecule $N$-(3-oxododecanoyl)-1-homoserine lactone has immunomodulatory activity. Infect Immun 66:36-42

Temprano A, Yugueros J, Hernanz C, Sanchez M, Berzal B, Luengo JM, Naharro G (2001) Rapid identification of Yersinia ruckeri by PCR amplification of yruI-yruR quorum sensing. J Fish Dis 24:253-261

Throup JP, Winson MK, Bainton NJ, Bycroft BW, Williams P, Stewart GSAB (1995) Signalling in bacteria beyond luminescence. In: Cambell AK, Kricka LJ, Stanley PE (eds) Bioluminescence and chemiluminescence: fundamental and applied aspects. Wiley, Chichester, p 89-92

Tsoumas A, Alderman DJ, Rodgers CJ (1989) Aeromonas salmonicida: development of resistance to 4-quinolone antimicrobials. J Fish Dis 12:493-507

Whitehead NA, Barnard AML, Slater H, Simpson NJL, Salmond GPC (2001) Quorum-sensing in gram-negative bacteria. FEMS Microbiol Rev 25:365-404

Winans SC, Zhu J, More MI (1999) Cell density dependent gene expression by Agrobacterium tumefaciens during colonization of crown gall tumors. In: Dunny GM, Winans $\mathrm{SC}$ (eds) Cell-cell signaling in bacteria. Am Soc Microbiol (Wash DC), p 117-128

Submitted: August 15, 2004; Accepted: November 17, 2004 Proofs received from author(s): May 2, 2005 